\title{
Pulse micro-surfacing as nonconventional method within the comprehensive technology of the gas-turbine engine recovery
}

\author{
Yuriy Tarasenko ${ }^{1, *}$, Ludmila Krivina $^{1}$, and Sergei Kirikov ${ }^{1}$ \\ ${ }^{1}$ Institute of Applied Physics of the Russian Academy of Sciences, Nizhny Novgorod, Russia
}

\begin{abstract}
The results of the experimental studies on the choice of optimal surfacing material for a pulse micro-surfacing of the details made of monocrystal nickel superalloys are set out. The microstructure, the microhardness, the adhesion strength and the heat-resistant stability of the built-up zones have been analyzed. The results of the research have been introduced within the elaboration of technological process of recovering working capacity and prolongation of a resource of the first step working blades of gas turbines SGT-800 Siemens, having completed their operating life ( 23000 equivalent hours ).
\end{abstract}

\section{Introduction}

Nowadays, the renovation of the blading of gas-turbine engines is an urgent challenge for engine-building because of the acute lack of material and insufficient financial resources in Russia. Now, for the import substitution industrialization there is a pressing need for the life-time prolongation of imported gas-turbine engines which have been in service in Russia since the early 2000s. Periodic technical checkups show that, there are defects of mechanical, erosive and corrosion origin on the working surface of turbine blades in a postoperational state. As a rule, a traditional method of an argon-arc surfacing is used at restoration of geometrical sizes and elimination of defect zones on blades during the repair process. This method of a surfacing is unacceptable for such important details like the first step working blades of the gas turbines SGT-800 (Siemens production) of power stations, as it is followed by formation of a distinct zone of thermal influence. In the blades, made by method of a gradient directional crystallization of heat-resistant monocrystal nickel alloy, the argon-arc overlaying can lead to the changes of a dendritic structure of a monocrystal. That's why, ensuring a reliable compound of two materials on the first step working blades, which are used in an extreme external environment $\left(\sim 1000{ }^{\circ} \mathrm{C}\right)$ is difficult, but nevertheless is a solvable task. For the solution of this problem, it is offered to use a new technology of a pulse micro-surfacing and individual approach at the choice of surfacing material. The available conventional surfacing materials provide a seam with relative chemical composition and mechanical characteristics to the basic metal. Within the technological process there is a great amount of factors such as realization conditions of the surfacing

* Corresponding author: npktribonika@yandex.ru 
works, quality of the used materials, protection of an alloyage zone, thermomechanical influence, etc. which can lead to reduced quality of a compound.

The method of a pulse micro-surfacing has such important advantages as local heating of base material, allowing to reduce considerably the size of a thermal influence zone and warping of a product, opportunity of receiving a quality surfacing of thin-walled details, various configurations of seams and their positions. Application of a pulse micro-surfacing allows to reduce considerably the labor intensity and input prices of repair because of an exception of a production cycle of prewarming, the subsequent thermal annealing and minimization of expenses for the subsequent machine work.

\section{Methods and discussion on the results}

This work deals with the selection of the optimal surfacing material for pulsed microsurfacing in the process of the restoring to working condition and the prolongation of the service life of SGT-800 Siemens SGT-800 blades, which have operated the assigned life 23,000.

Model samples of monocrystal heat-resistant nickel alloy ZhS30 were objects of the research. The following wire goods were tested as surfacing materials:

- heat-resistant nickel alloy EP648;

- material based on cobalt of the mark 2748-00;

- monocrystal heat-resistant nickel alloy ZhS32.

The element composition of the used materials is given in table 1 .

Table 1. Element composition of materials.

\begin{tabular}{|l|l|l|l|l|l|l|l|l|l|l|l|}
\hline $\begin{array}{l}\text { Eleme } \\
\text { nt, \% }\end{array}$ & $\mathrm{Ni}$ & $\mathrm{Cr}$ & $\mathrm{Al}$ & $\mathrm{Ti}$ & $\mathrm{Nb}$ & $\mathrm{Mo}$ & $\mathrm{W}$ & $\mathrm{C}$ & $\mathrm{Co}$ & $\mathrm{Ce}$ & $\mathrm{Si}$ \\
\hline ZhS30 & $\begin{array}{l}56,2- \\
65,4\end{array}$ & $5-9$ & $\begin{array}{l}4,8- \\
5,\end{array}$ & $\begin{array}{l}1,4- \\
2,3\end{array}$ & $\begin{array}{l}0,4- \\
1,4\end{array}$ & -- & $\begin{array}{l}11- \\
12,6\end{array}$ & $\begin{array}{l}0,11- \\
0,2\end{array}$ & $\begin{array}{l}7,5- \\
9,5\end{array}$ & 0,015 & --- \\
\hline ZhS32 & base & 4,9 & 5,9 & & 1,6 & 1,0 & 8,5 & 0,15 & 9,0 & 0,025 & -- \\
\hline EP648 & basis & $\begin{array}{l}32 \\
0-\end{array}$ & $\begin{array}{l}0,5- \\
1,1\end{array}$ & $\begin{array}{l}0,5- \\
1,1\end{array}$ & $\begin{array}{l}0,5- \\
1,1\end{array}$ & $\begin{array}{l}2,3- \\
3,3\end{array}$ & $\begin{array}{l}4,3- \\
5,3\end{array}$ & $\leq 0,10$ & -- & -- & -- \\
& & 35,0 & & & & & & & & \\
\hline $\begin{array}{l}2748- \\
00\end{array}$ & --- & 30,0 & --- & --- & --- & --- & 12,5 & 2,4 & base & --- & 1, \\
\hline
\end{tabular}

Surfacing works were carried out with the device of a pulse micro-surfacing NOVAPAX SW-V01.

Microstructure of the basic and built up metals, zones of material's compound were studied on an optical microscope "Neophot-32".

Microhardness $\left(\mathrm{H}_{\mu}\right)$ was measured with the aid of micro-hardness tester PMT-3 at loading $1 \mathrm{~N}$ in accordance with the State Standard 9450-76.

The adhesion strength in the surfacing zone was tested on the cross metallographic section by the method of micro-indentation on a microhardness tester PMT-3 at loading $2 \mathrm{~N}$ on the indentor.

The heat-resistance of the built-up samples was tested in accordance with the method of isothermal endurance in the electric furnace with the air atmosphere at a temperature of $1000^{\circ} \mathrm{C}$ within 300 hours.

Borders of the built-up zone and microstructure of materials in the built-up zone are presented in fig. 1.

Values of microhardness of the basic and built up materials in the initial state are given in fig. 2 


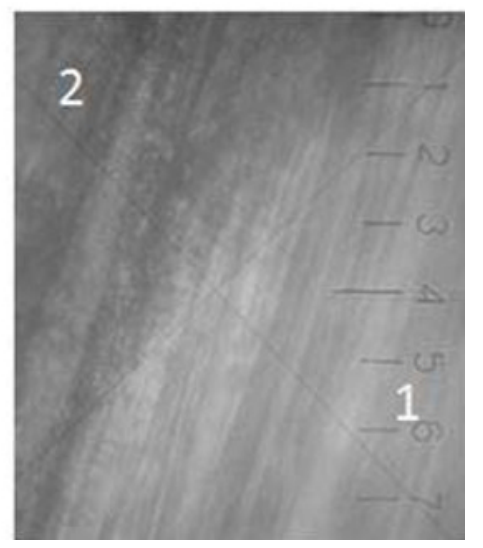

a

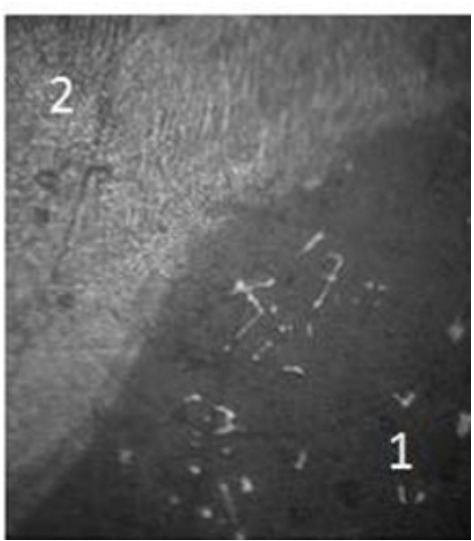

b

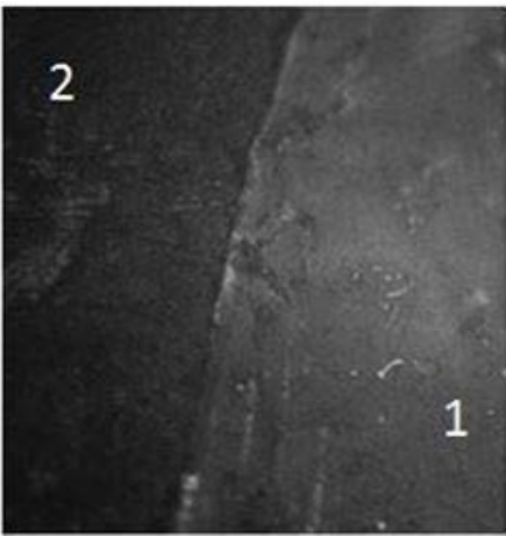

$\mathrm{C}$

Fig. 1. Structure of a basic monocrystal alloy material $\mathrm{ZhS30} \mathrm{(1)} \mathrm{and} \mathrm{the} \mathrm{built-up} \mathrm{materials} \mathrm{(2)} \mathrm{in}$ the initial state: a -nickel alloy EP648; b - material based on cobalt of the mark 2748-00; c monocrystal heat-resistant nickel alloy ZhS32, (X500).

$$
\mathrm{H}_{100}, \mathrm{~kg} / \mathrm{mm}^{2} \quad \square \text { base material } \quad \text { the built-up material }
$$

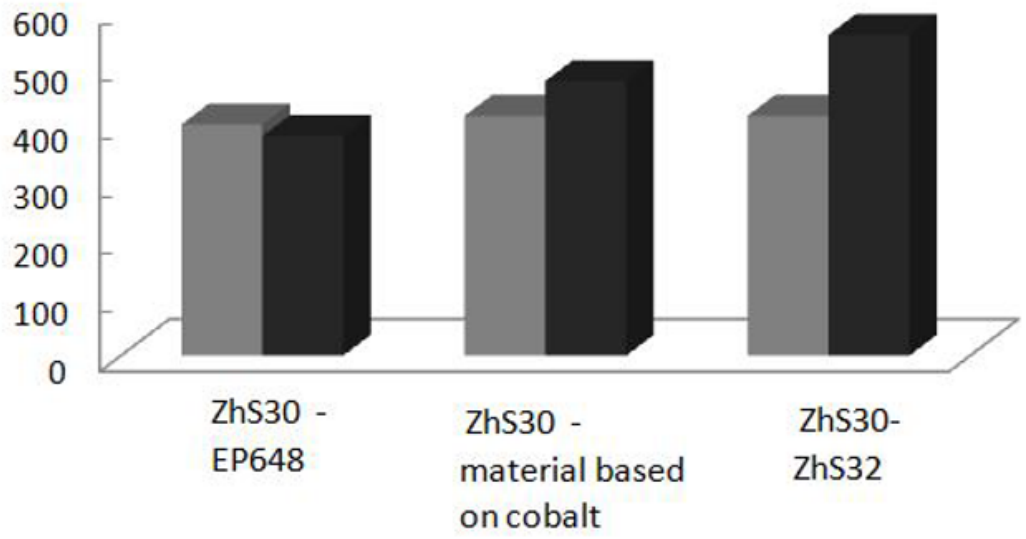

Fig. 2. The chart of a microhardness of the basic and built up materials in the initial state. 
The analysis of a micro-indentation of the interface of the built-up cobalt material with the basic metal has demonstrated an unsatisfactory adhesion strength which was shown in stratifications on border. High cohesive strength at the interface is reached at the surfacing by high-temperature alloys based on nickel (a wire EP648 and strips of monocrystal alloy ZhS32).

At tests of the adhesion strength (by the method of micro-indentation) cracks, chips, layer separations and distortions of a form of a print are not revealed at the interface "basic material ZhS30- built up material ZhS32". It is worth mentioning that measures of the microhardness have shown bigger variations in indices of hardness of the base and of built up material for the case of surfacing with the alloy $\mathrm{ZhS32}$ (fig.. 2).

Heat resistance tests of samples with different options of the built-up materials have shown that surfacing material made of alloy $\mathrm{ZhS} 32$ has higher resistance to hightemperature oxidation than EP648. The relative increase of sample's mass during the tests was $10 \%$ and $17 \%$ respectively.

Surfaced zone edges and microstructure of built up zone's materials are given in fig.3.

Using the surfacing materials EP648 and ZhS32 leads to the high temperature stability of a connection zone with a basic material. On a sample with a surfacing based on cobalt, high-temperature influence resulted in layer separation of the built-up zone from a substrate. (fig. 3b).

Values of a microhardness of the basic and built up materials after high-temperature tests are given in fig. 4.

After isothermal endurance at the temperature of $1000{ }^{\circ} \mathrm{C}$ decrease in microhardness was installed in the built-up zone of a sample with a surfacing made of monocrystal alloy $\mathrm{ZhS} 32$ and, as a result, equalizing of hardness values on the metallographic section in a transitional zone to the basic material is also observed.

It is worth mentioning that after carrying out the surfacing works the expressed zone of thermal influence has not been revealed in any tests conducted by the method of an optical metallography. In the original material $(\mathrm{ZhS} 30)$ the initial dendritic microstructure of monocrystal alloy remains next to the interface. It proofs the lack of the considerable temperature impact on an original material within a pulse surfacing.

It has been found that monocrystal alloy $\mathrm{ZhS} 32$ has the best resistance to hightemperature oxidation at temperatures of operation up to $1000{ }^{\circ} \mathrm{C}$ from all tested surfacing materials. The alloy EP648, which has good technological properties within surfacing works, can be applied under the condition of the restored details functioning between 800 $900{ }^{\circ} \mathrm{C}$. When a wire of the thickness $\sim 0,8 \mathrm{~mm}$ is used even the most minor defects can be eliminated successfully. Thus, pulse micro-surfacing with thin wire on the device Weldpro SW-V01 - is a good alternative to automatic argon-arc overlaying. 


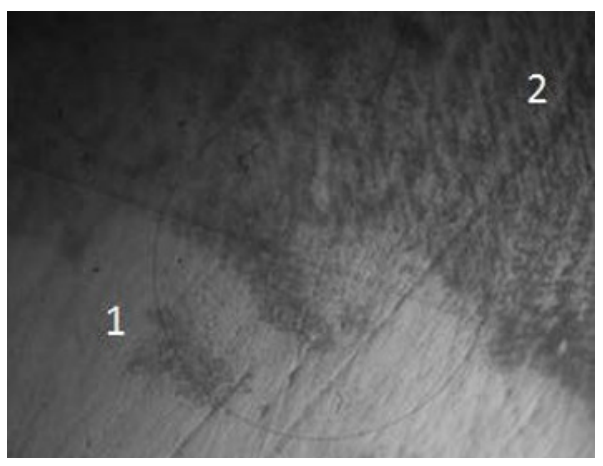

a

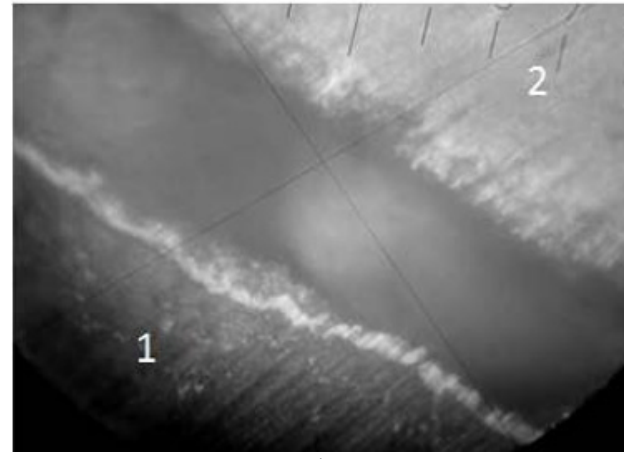

b

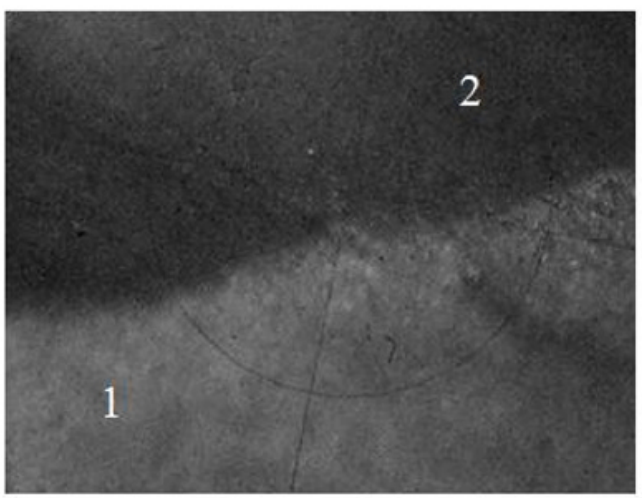

c

Fig. 3. Structures of a basic monocrystal alloy material $\mathrm{ZhS30} \mathrm{(1)} \mathrm{and} \mathrm{the} \mathrm{built-up} \mathrm{materials} \mathrm{(2)} \mathrm{after}$ high-temperature tests: a - built-up materials made of alloy EP648; b - built-up material based on cobalt; c - built-up material of alloy ZhS32, (X500).

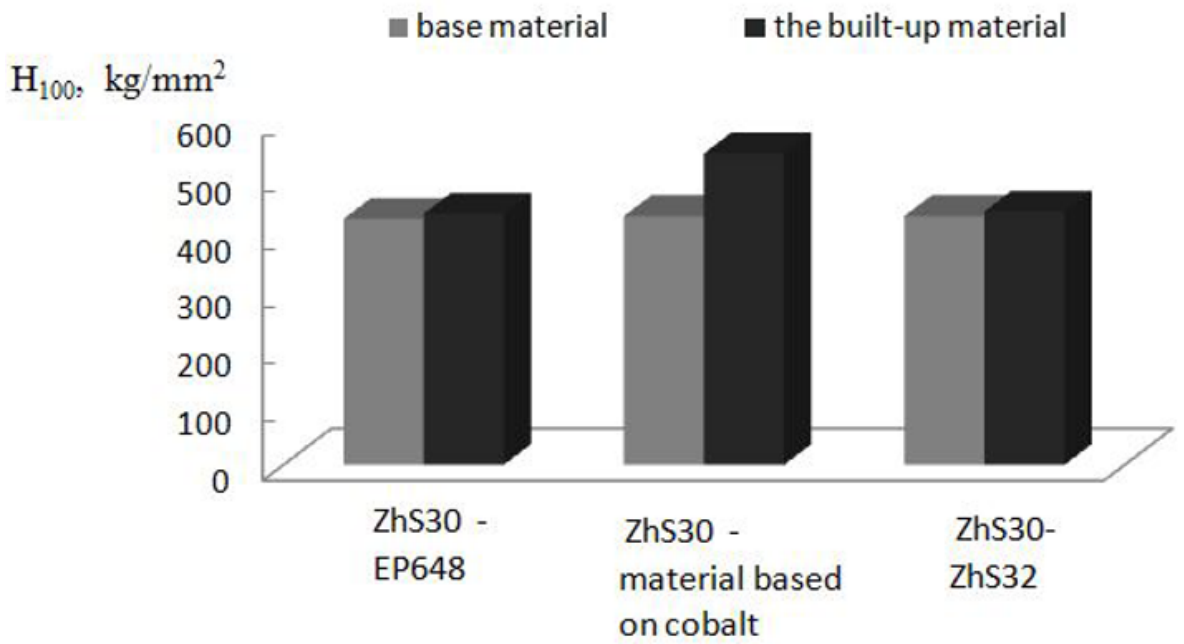

Fig. 4. The chart of a microhardness of the basic and built up materials after tests of heat-resistance. 


\section{Conclusion}

The received results of researches have been used in developing technological process of repair and recovery operations for the working blades of the gas turbines SGT-800 Siemens. The Technology was introduced into LLC "CityEnergo" (Moscow) during the renovation of the working blades of the first step SGT-800.

Work is performed within the Institute of Applied Physics of the Russian Academy of Sciences state task for carrying out basic scientific research for 2013-2020 on a subject No. 0035-2014-0401 (No. of state filing 01201458049)

\section{References}

1. Y.P. Tarasenko, S.V. Kirikov, O.B. Berdnik, L.A. Krivina, Otsenka of a possibility of maintenance of material of shovels of turbines of power stations by methods of the quantitative analysis of the strengthening phases and researches of local mechanical characteristics//Questions of materials science, v. 2(90), pp. 49 - 57 ( 2017)

2. O.B. Berdnik, I.N. Tsareva, Y.P. Tarasenko, S.V. Kirikov, L.A. Krivina, Analiz of a post-operational condition of turbine shovels of SGT-800 Siemens and development of technology of extension of their resource, Basic Researches and Innovative Technologies in Mechanical Engineering, Moscow, IMASh RAS, pp. 54-55 (2017) 